\title{
Who benefit from school doctors' health checks: a prospective study of a screening method
}

\author{
Kirsi Nikander ${ }^{1,2^{*}}$ (D), Silja Kosola ${ }^{3,4}$, Minna Kaila $^{5}$ and Elina Hermanson ${ }^{6}$
}

\begin{abstract}
Background: School health services provide an excellent opportunity for the detection and treatment of children at risk of later health problems. However, the optimal use of school doctors' skills and expertise remains unknown. Furthermore, no validated method for screening children for school doctors' assessments exists. The aims of the study are 1) to evaluate the benefits or harm of school doctors' routine health checks in primary school grades 1 and 5 (at ages 7 and 11) and 2) to explore whether some of the school doctors' routine health checks can be omitted using study questionnaires.

Methods: This is a prospective, multicenter observational study conducted in four urban municipalities in Southern Finland by comparing the need for a school doctor's assessment to the benefit gained from it. We will recruit a random sample of 1050 children from 21 schools from primary school grades 1 and 5 . Before the school doctor's health check, parents, nurses and teachers fill a study questionnaire to identify any potential concerns about each child. Doctors, blinded to the questionnaire responses, complete an electronic report after the appointment, including given instructions and follow-up plans. The child, parent, doctor and researchers assess the benefit of the health check. The researchers compare the need for a doctor's appointment to the benefit gained from it. At one year after the health check, we will analyze the implementation of the doctors' interventions and follow-up plans.
\end{abstract}

Discussion: The study will increase our knowledge of the benefits of school doctors' routine health checks and assess the developed screening method. We hypothesize that targeting the health checks to the children in greatest need would increase the quality of school health services.

Trial registration: ClinicalTrials.gov Identifier: NCT03178331, date of registration June $6^{\text {th }} 2017$.

Keywords: Children, Student, Questionnaires, Screening, Health check, School health services

\section{Background}

School health services provide an excellent opportunity for the detection and treatment of children and young people at risk of later health problems [1]. Globally, the organization, financing and the functions of school health services vary significantly $[2,3]$. According to a recent systematic review, health promotion interventions in schools have been effective in decreasing body mass

\footnotetext{
* Correspondence: kirsi.nikander@iki.fi

${ }^{1}$ School and Student Healthcare, Department of Social Services and Healthcare, City of Helsinki, Finland

${ }^{2}$ Doctoral School in Health Sciences, Doctoral Program in Population Health, University of Helsinki, Helsinki, Finland

Full list of author information is available at the end of the article
}

index, increasing physical activity levels, and decreasing experiences of being bullied [4].

The optimal use of the school doctors' skills and expertise remains unknown. A systematic review in the UK demonstrated that evidence is insufficient to assess the effectiveness of either the routine or selective school entry medical examination [5]. In a study from the Netherlands, doctor's assistants carried out pre-assessments instead of all children being screened by a nurse or a doctor. This triage approach resulted in lower referral rates [6] and a cost reduction of about one-third [7] compared with usual practice.

(c) The Author(s). 2018 Open Access This article is distributed under the terms of the Creative Commons Attribution 4.0 International License (http://creativecommons.org/licenses/by/4.0/), which permits unrestricted use, distribution, and 
Overweight, visual disorders and psychosocial problems were detected similarly in both groups [8].

According to Finnish law, the public preventive health care system of children between ages 0-6 years (Well Child Clinic) offers at least 15 routine health checks by the nurse and 5 health checks by the doctor, free of charge. School nurses, trained in health promotion and preventive care, arrange annual health checks in all grades of primary school. The health checks in grades 1 , 5 and 8 (at ages 7, 11 and 14 years, respectively) are called "extensive health checks". The parents are invited to participate. Both the school nurse and the school doctor assess the well-being of all children and young people in those grades (Fig. 1). Table 1 describes the division of labor in primary school grades 1-6. Most of the school doctor resources in primary schools are allocated to "extensive health checks" regardless of previously identified health risks. Children in other grades receive only very limited school doctor services although the special needs of all children should be recognized and help provided timely. When a special need is recognized and more time required to treat it, some of the school doctor's obligatory health checks may be omitted randomly or the family may be instructed to contact the public health center or the private sector for help. The overall efficiency or the cost effectiveness of the Finnish school healthcare system has not been evaluated thus far. Currently, no validated method exists for screening children for school doctors' assessments.

The primary aims of this study are 1) to evaluate the potential benefits or harm of school doctors' routine health checks in primary school grades 1 and 5 (at ages 7 and 11 years, respectively and 2) to explore whether some of the school doctors' routine health checks in those grades can be omitted using study questionnaires that assess the parents', school nurses', and teachers' potential concerns regarding each child. The secondary aim is to evaluate the implementation of the school doctors' interventions and follow-up plans at one year after the health check.

\section{Methods \\ Study design}

This is a prospective, observational, multicenter study which is conducted by comparing the need for a doctor's appointment based on the study questionnaires to the benefit or harm gained from the doctor's appointment as assessed by the doctor, parent, child and researchers (Fig. 2). Under the current legislation in Finland, omitting some of the school doctor's obligatory health checks and comparing groups of children who undergo a health check to children who do not undergo one cannot be done. To circumvent this problem, the school doctor's check is arranged to all children, as usual, without knowledge of the content of the previously filled study questionnaires. At one year after the health check, the implementation of the doctors' interventions and follow-up plans will be analyzed.

\section{Study participants}

This study is conducted in primary schools of four urban municipalities in Southern Finland. One municipality

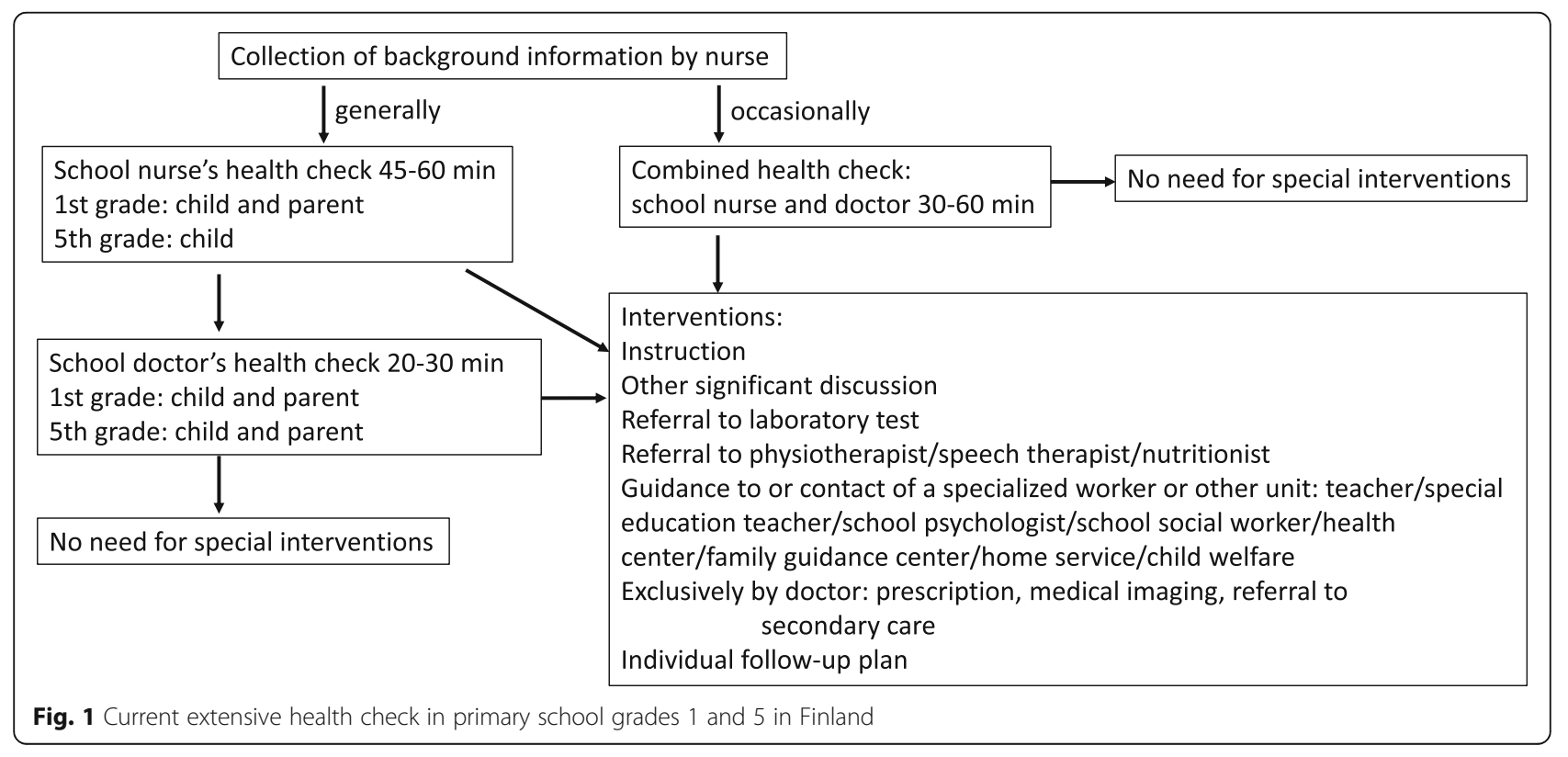


Table 1 Division of labor in school health services in primary school grades 1-6 in Finland ${ }^{a}$

\begin{tabular}{|c|c|c|}
\hline Tasks & $\begin{array}{l}\text { School } \\
\text { nurse }\end{array}$ & $\begin{array}{l}\text { School } \\
\text { doctor }\end{array}$ \\
\hline Extensive health examinations in grades 1 and 5 & $x$ & $x$ \\
\hline $\begin{array}{l}\text { Collection of background information for the } \\
\text { extensive health examinations }\end{array}$ & $x$ & \\
\hline \multicolumn{3}{|l|}{$\begin{array}{l}\text { Well Child Clinic (pregnancy and birth, } \\
\text { biopsychosocial development) }\end{array}$} \\
\hline \multicolumn{3}{|c|}{$\begin{array}{l}\mathrm{THL}^{\mathrm{b}} \text { questionnaire by parent (1st and 5th grade), child (5th grade) } \\
\text { and teacher (some schools) }\end{array}$} \\
\hline \multicolumn{3}{|l|}{ Statements from the student welfare group } \\
\hline $\begin{array}{l}\text { Evaluation: growth, vision, hearing, blood pressure, } \\
\text { posture }\end{array}$ & $x$ & \\
\hline Complementation of background information & & $x$ \\
\hline $\begin{array}{l}\text { Evaluation of growth, somatic, psychiatric and } \\
\text { neurologic status }\end{array}$ & & $x$ \\
\hline Diagnostics and differential diagnostics & & $x$ \\
\hline Vaccinations & $x$ & \\
\hline $\begin{array}{l}\text { Referrals to physiotherapist, speech therapist, } \\
\text { nutritionist }\end{array}$ & $x$ & $x$ \\
\hline Referrals to secondary care & & $x$ \\
\hline $\begin{array}{l}\text { Guidance to or contact of specialized workers/other } \\
\text { units }\end{array}$ & $x$ & $x$ \\
\hline \multicolumn{3}{|c|}{$\begin{array}{l}\text { Teacher/special education teacher/school psychologist/school } \\
\text { social worker }\end{array}$} \\
\hline \multicolumn{3}{|l|}{ Health center } \\
\hline \multicolumn{3}{|l|}{ Family guidance center/Social worker/Home service } \\
\hline \multicolumn{3}{|l|}{ Child welfare } \\
\hline Referrals to laboratory tests & $x$ & $x$ \\
\hline Referrals to medical imaging & & $x$ \\
\hline $\begin{array}{l}\text { Annual health checks (the general wellbeing, growth, } \\
\text { eating, exercise and sleeping habits, friendships and } \\
\text { hobbies) }\end{array}$ & $x$ & \\
\hline Prescriptions & & $x$ \\
\hline Health education and support & $x$ & $x$ \\
\hline Evaluation of special needs in all grades & $x$ & $x$ \\
\hline Control visits & $x$ & $x$ \\
\hline Participation in student welfare groups ${ }^{c}$ & $x$ & $x$ \\
\hline
\end{tabular}

a Local variations may exist

${ }^{\mathrm{b}} T H L$ The National Institute for Health and Welfare

${ }^{c}$ Evaluate and develop the well-being of school community and students (permanent members: school principal, special education teacher, school psychologist, school social worker, school nurse)

(Helsinki) has a system of exclusive school doctor services (i.e. physicians working solely as school doctors), whereas in three municipalities (Tampere, Kerava and Kirkkonummi) physicians also serve other population groups. All the children who met the inclusion criteria were given a computer generated random number by the study nurse. The first 30 children in each school and their parents were asked to participate. If more than 5 families did not participate, more children were recruited from the random order list. From each school, we will recruit at least 25 randomly selected children from grade 1 and 25 children from grade 5 . Thus, the number of recruited children will be 1050 from 21 schools.

Fourteen doctors are participating in the study. Figure 3 depicts the flow chart of population-based recruitment and Fig. 4 outlines the recruitment of doctors.

Exclusion criteria are children studying mainly in special education groups and the need of an interpreter. The study is limited to Finnish speaking schools.

\section{Data collection procedure}

Prior to the beginning of children's recruitment, informed consent was obtained from all participating school nurses, teachers and doctors. School doctors filled a short form regarding their education and work experience. KN signed the school nurses' and doctors' consent forms. The teachers consent forms were signed by $\mathrm{KN}$ or the research assistant.

School nurses fill in study questionnaires (nurse's questionnaire, NQ) after they have performed their part of the children's extensive health check. The nurses store the NQs separate from the regular patient files. Before the school doctors' health checks, nurses check the NQs to make sure that the information is up to date and mail the families study information, consent forms and study questionnaires (parent's questionnaire, $\mathrm{PQ}$ ). The participating school nurses sign the parents' and children's consent forms. The parents and children return their consent forms and the PQs to a sealed box in the waiting room before the doctor's appointment. If the family has forgotten or lost their forms and PQs, they may fill them just before the doctor's appointment. The nurses also deliver study questionnaires to the teachers (teacher's questionnaire, TQ) who return them to the researchers by mail.

School doctors perform the health checks as usual without knowledge of the content of the study questionnaires $(\mathrm{NQ}, \mathrm{PQ}, \mathrm{TQ})$. After each health check, doctors fill an electronic report including given instructions, significant discussions and follow-up plans (Fig. 1, box Interventions). In addition, school doctors report their estimate of the benefit or harm of the medical appointment based on the criteria defined by the researchers. Parents and children fill patient-reported experience measures (PREMs) regarding the benefit or harm of the doctor's appointment.

School nurses inform the researchers about families that do not wish to participate and the reason for not participating (no consent, has moved from area/school, non-attendance at appointment). If the family doesn't 


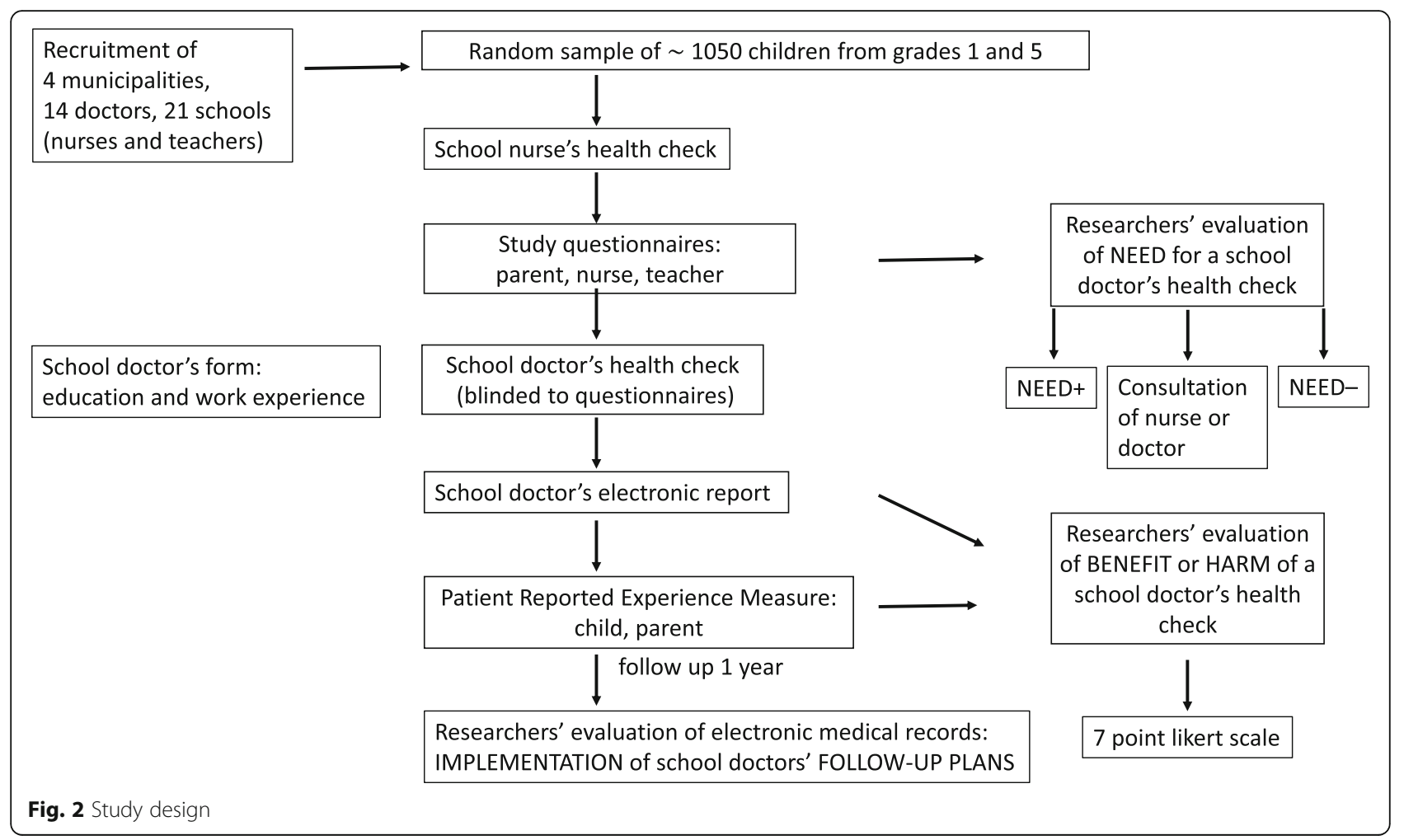

consent to the study, the nurse's and teacher's questionnaires are destroyed.

Data will be collected from doctors, children, parents/ carers, teachers and nurses in 2017-2018 (Fig. 5). Date of enrolment of the first participant was August 22nd, 2017.
To evaluate the implementation of the doctors' care/treatment plans, the children's electronic medical records will be assessed after one year's follow-up. The exact study plan for this remains to be finalized. Additional file 1 outlines the Information sources and Data collection objects.

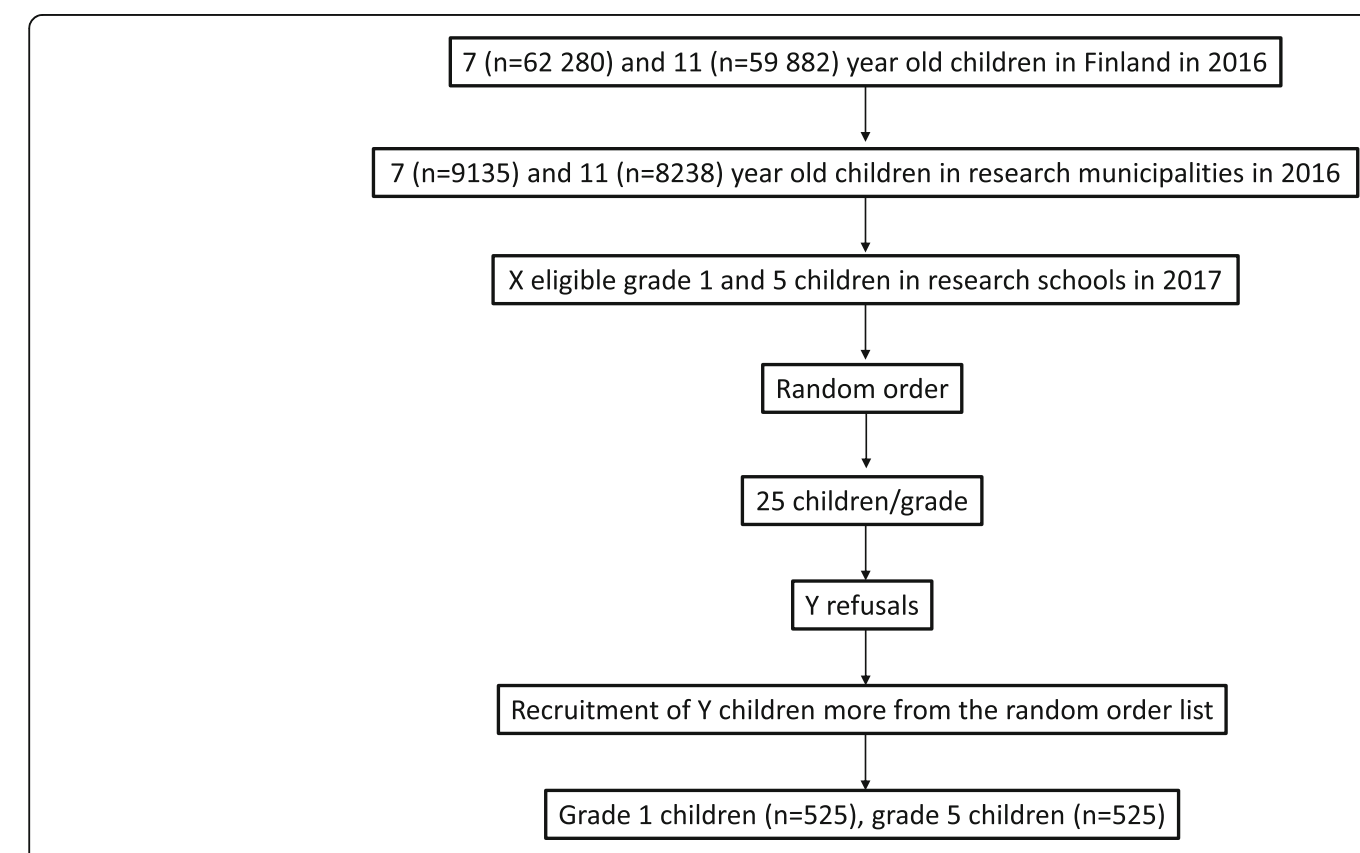

Fig. 3 Flow chart of population-based recruitment 


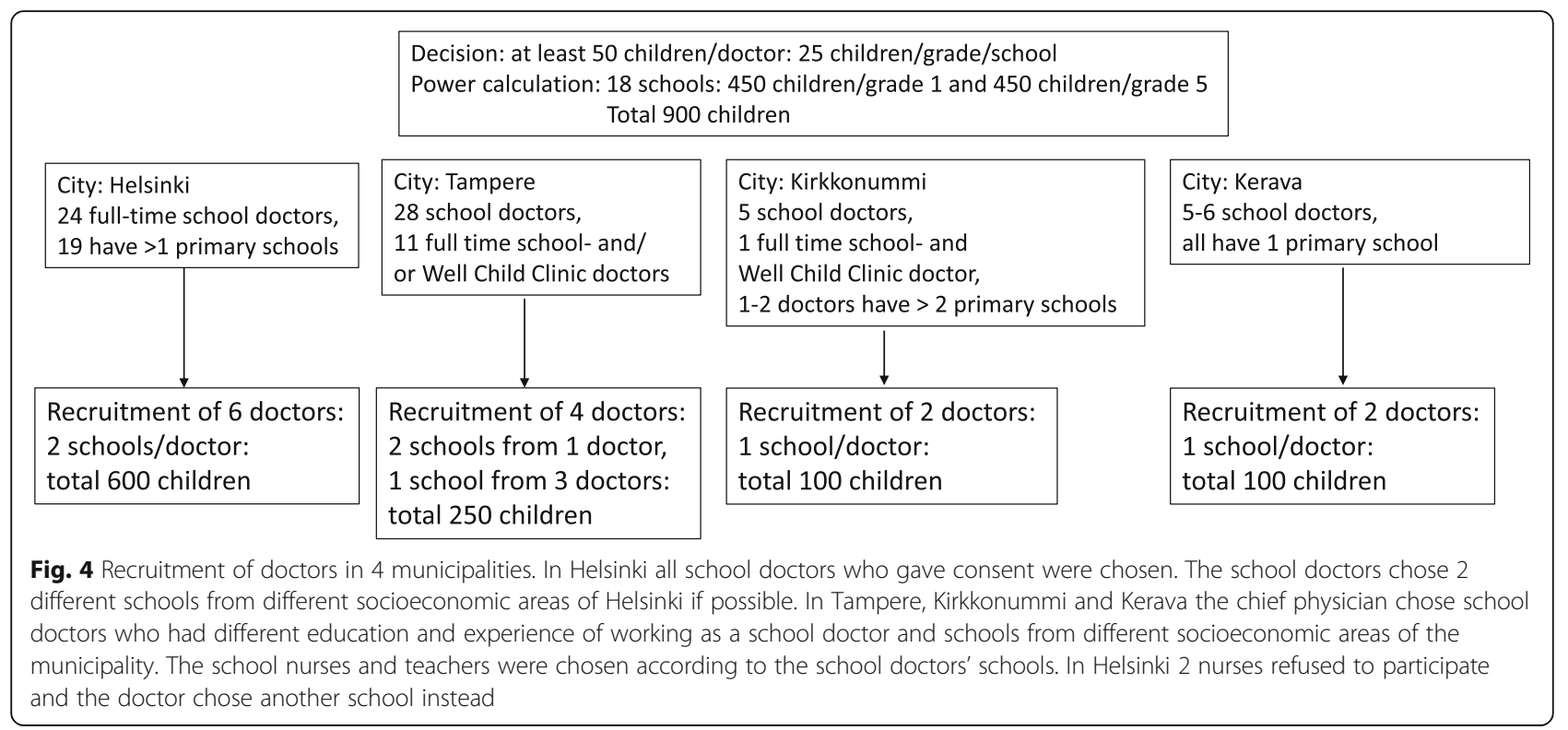

\section{Study questionnaires}

The study questionnaires address parents' (PQ), school nurses' (NQ) and teachers' (TQ) concerns regarding each child's physical and mental health and the wellbeing of the whole family (Table 3). See Additional files 2, 3, 4 for the English versions of the study questionnaires. The questions were partly chosen from the Strengths and Difficulties Questionnaire (SDQ) which is a validated screening method for children's psychiatric disorders [9]. One of the questions of the SDQ is almost as reliable as the complete SDQ [10-12]. That question evaluates whether the child has difficulties in one or more of the following areas: emotions, concentration, behavior, or being able to get on with other people. It was divided into four questions in the study questionnaires. Additional questions, regarding the child's growth, physical well-being, eating, sleeping, learning, school absenteeism, and the

\begin{tabular}{|l|l|}
\hline 2015 & $\begin{array}{l}\text { Ethics approval for pilot study } \\
\text { Questionnaire development }\end{array}$ \\
2016 & $\begin{array}{l}\text { Ethics approval for multicenter study } \\
\text { Data collection from questionnaires, } \\
\text { patient reported experience measures } \\
\text { and doctors' electronic reports } \\
2018\end{array}$ \\
2019 & $\begin{array}{l}\text { Data collection from electronic medical records } \\
\text { Fig. } 5 \text { Timeline of the study }\end{array}$ \\
\hline
\end{tabular}

well-being of the whole family, were also included based on previous evidence [13-18] and clinical knowledge of the research group and piloted.

\section{Study questionnaire, PREM and doctors' electronic report development}

Study questionnaires for parents, nurses and teachers and a doctor's electronic report were developed between June and August 2015. The feasibility of the questionnaires and the electronic report was tested in a pilot study between November 2015 and May 2016 by one school doctor $(\mathrm{KN})$ in three primary schools in Helsinki. Of the 147 families contacted, 132 (90\%) chose to participate. In addition, three nurses and 15 teachers participated in this phase. Based on the pilot study, the questionnaires were slightly modified to better suit their purpose.

Two researchers (KN and $\mathrm{EH})$ reviewed the questionnaires. The research group categorized the responses into three groups: 1) "Needs doctor's health check" 2) "No need for doctor's health check" and 3) "Consultation of the nurse by parent or consultation of the doctor by nurse or teacher may be sufficient". The free description of the concern can alter the categorization (Figs. 6 and 7). Depending on the outcome of the consultation, a nurse's or doctor's appointment would be arranged for the child and parent if needed.

Based on the experience gained in the pilot study the criteria for the doctors' and researchers' evaluation of benefit and harm were defined (Table 2). Space was also provided for free responses of benefit or harm for all respondents.

The research group developed patient-reported experience measures (PREMs) for the parent and child to enable 


\begin{tabular}{|c|c|}
\hline \multicolumn{2}{|l|}{ Quite a lot/A great deal of concern } \\
\hline \multirow{2}{*}{$\begin{array}{l}\text { 3 or more responses: Only a little concern } \\
\text { AND } \\
\text { Wish for school doctor's assessment of these or other concerns }\end{array}$} & \multirow[t]{2}{*}{ NEED + } \\
\hline & \\
\hline \multirow[t]{2}{*}{$\begin{array}{l}\text { 3 or more responses: Only a little concern } \\
\text { AND } \\
\text { Cannot say about a wish for school doctor's assessment }\end{array}$} & \\
\hline & *CONSULTATION of nurse or doctor \\
\hline \multicolumn{2}{|l|}{$\begin{array}{l}2 \text { or less responses Only a little concern } \\
\text { AND } \\
\text { Wish for school doctor's assessment of these or other concerns }\end{array}$} \\
\hline $\begin{array}{l}2 \text { or less responses Only a little concern } \\
\text { AND } \\
\text { No wish/Cannot say about a wish for school doctor's assessment }\end{array}$ & \\
\hline \multicolumn{2}{|l|}{$\begin{array}{l}\text { Only responses: Not at all/Only a little/I don't know about concern } \\
\text { AND } \\
\text { No wish for school doctor's assessment of these or other concerns }\end{array}$} \\
\hline $\begin{array}{l}\text { Fig. } 6 \text { Categorization of parent's and nurse's study questionnaire responses. }{ }^{*} \text { The } \\
\text { 1) NEED+ for school doctor's health check: If there is concern such as parenthood } \\
\text { oehavior problems in the class, recurrent joint pain/headaches, heel pain, acne, a } \\
\text { only little concern about growth or posture and a wish for school doctor's assessn } \\
\text { growth but the nurse is not concerned about it, the amount of sleeping, growth }\end{array}$ & $\begin{array}{l}\text { the concern can alter the categorization to } \\
\text { between parent and child, sleep problems, } \\
\text { ATION, (a) of doctor by nurse if the nurse has } \\
\text { Dy parent if the parent has concern about: }\end{array}$ \\
\hline
\end{tabular}

the evaluation of the parents' and child's perception of benefit or harm of the doctor's health check. The response options for parents were the same as for doctors and researchers but without previously defined criteria (Table 2). In addition to a verbal scale, visual analogues in the form of facial expressions were included for children. Borg gave permission to use the same facial expression models that she used for the "Child's self-evaluation enquiry on emotional well-being" [12]. See Additional file 5 and Additional file 6 for the English versions of the PREMs.

\section{Quite a lot/A great deal of concern \\ OR \\ 3 or more responses: Only a little concern}

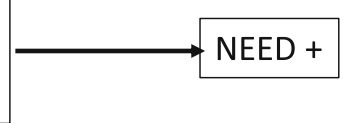

\section{2 or less responses Only a little concern AND}

Wish for school doctor's assessment of these or other concerns

\section{2 or less responses Only a little concern \\ AND \\ No wish/Cannot say about a wish for school doctor's assessment}

\section{*NEED -}

Fig. 7 Categorization of teacher's study questionnaire responses. *The free description of the concern can alter the categorization to NEED+ for school doctor's health check: If there is concern such as parenthood or the relationship between parent and child, sleep problems, behavior problems in the class, recurrent joint pain/headaches, heel pain, acne, a mole 
Table 2 Criteria of benefit and harm and Patient reported experience measures (PREMs)

\begin{tabular}{|c|c|c|c|c|c|c|c|c|}
\hline & \multicolumn{7}{|c|}{ Response options for doctors and researchers ${ }^{b}$} & \\
\hline & \multicolumn{4}{|l|}{ Benefit } & \multicolumn{4}{|l|}{ Harm } \\
\hline & $\begin{array}{l}\text { A great } \\
\text { deal }\end{array}$ & $\begin{array}{l}\text { Quite } \\
\text { a lot }\end{array}$ & $\begin{array}{l}\text { Only a } \\
\text { little }\end{array}$ & $\begin{array}{l}\text { No benefit } \\
\text { or harm }\end{array}$ & Only a little & Quite a lot & A great deal & \\
\hline \multicolumn{9}{|l|}{ Criteria for doctors and researchers } \\
\hline $\begin{array}{l}\text { 1. Significant discussion }{ }^{\mathrm{a}} \text { or other intervention } \\
\text { that presumably reduces } \\
\text { other health care use }\end{array}$ & $x$ & & & & & & & \\
\hline 2. Need to contact child welfare & $x$ & & & & & & & \\
\hline 3. Some referrals to secondary care & $x$ & $x$ & & & & & & \\
\hline 4. Doctor's role irreplaceable by nurse & & $x$ & & & & & & \\
\hline 5. Presumably reduced concern ${ }^{\mathrm{b}}$ & & $x$ & & & & & & \\
\hline 6. Some significant discussions ${ }^{\mathrm{b}}$ & & $x$ & & & & & & \\
\hline 7. Nurse could have replaced the doctor & & & $x$ & & & & & \\
\hline $\begin{array}{l}\text { 8. No significant harm as consequence of } \\
\text { unhandled concerns }\end{array}$ & & & $x$ & & & & & \\
\hline $\begin{array}{l}\text { 9. Suspicion that interaction failed or suspicion } \\
\text { of no progress in care }\end{array}$ & & & & & $x$ & & & \\
\hline $\begin{array}{l}\text { 10. The interaction failed or here was no } \\
\text { progress in care }\end{array}$ & & & & & & $x$ & & \\
\hline $\begin{array}{l}\text { 11. Suspicion of negative PREM or refusal } \\
\text { of school doctor services in the future and } \\
\text { no progress in care }\end{array}$ & & & & & & & $x$ & \\
\hline \multicolumn{9}{|l|}{ PREM question } \\
\hline $\begin{array}{l}\text { How much benefit or harm did you perceive } \\
\text { from the school doctor's health check? }\end{array}$ & & & & & & & & I don't know \\
\hline Response options for parents & $x$ & $x$ & $x$ & $x$ & $x$ & $x$ & $x$ & $x$ \\
\hline Response options for children & & $x$ & $x$ & $x$ & $x$ & $x$ & & \\
\hline $\begin{array}{l}\text { aRelates to a different subject than an instruction, a } \\
\text { Additional criteria: } \\
\text { The child's or parent's concern reduced significantly } \\
\text { The child or parent realized something new that im } \\
\text { The child or parent made a decision towards a heal } \\
\text { bThe researchers take the PREMs into account wher } \\
\text { If the parent's PREM is between "Only a little benefi } \\
\text { The child's PREM will be analyzed separately in a sir } \\
\text { All responses of harm will be analyzed individually }\end{array}$ & $\begin{array}{l}\text { orescription } \\
\text { or their res } \\
\text { roves their } \\
\text { ier lifestyl } \\
\text { considering } \\
\text { ' and "A gre } \\
\text { ilar fashion }\end{array}$ & $\begin{array}{l}\text { or a refer } \\
\text { urces stre } \\
\text { well-bein } \\
\text { the valu } \\
\text { at deal o }\end{array}$ & $\begin{array}{l}\text { al; } \\
\text { ngthen } \\
\text { or } \\
\text { of disc } \\
\text { harm", }\end{array}$ & $\begin{array}{l}\text { ns } \\
\text { alue of } d i\end{array}$ & ons canno & igher that & ly a little be & \\
\hline
\end{tabular}

\section{Questionnaire delivery}

The pilot study demonstrated a need for thorough instructions to all participating families and professionals. If the study questionnaire is completed too early, the likelihood of changes in the child's health and life situation increases. The nurses were therefore instructed to check the previously filled NQ and to deliver the TQ just prior to sending the invitation letter to the parents. The teachers were instructed to return the TQs within one week.

Detailed written instructions and training sessions were arranged for school nurses $(1.5 \mathrm{~h})$, teachers (15 $\mathrm{min})$ and school doctors $(1-1.5 \mathrm{~h})$ prior to the multicenter study. $\mathrm{KN}$ is available to answer questions from the participating nurses, school doctors, teachers and parents during the whole data collection period via phone or e-mail.

\section{Measures \\ Primary outcomes}

The primary outcome measures are 1) the need for a school doctor's health check and 2) the benefit/harm of school doctors' routine health checks.

The need for the doctor's health check is determined based on the parents', teacher's and nurse's study questionnaires (Table 3 ). The responses will be categorized into three groups: 1) "Needs doctor's health check" 2) "No need for doctor's health check" and 3) "Consultation of the nurse or doctor may be sufficient" (Figs. 6 and 7). 
Table 3 Areas of concern in the study questionnaires according to respondent

\begin{tabular}{|c|c|c|c|}
\hline Areas of concern $^{a}$ & Parent & Nurse & Teacher \\
\hline Child's growth & $x$ & $x$ & \\
\hline physical symptom(s) ${ }^{\mathrm{b}}$ & $x$ & $x$ & $x$ \\
\hline hearing & & $x$ & \\
\hline school absenteeism & $x$ & & $x$ \\
\hline learning & $x$ & & $x$ \\
\hline concentration & $x$ & $x$ & $x$ \\
\hline behavior & $x$ & $x$ & $x$ \\
\hline emotions & $x$ & $x$ & $x$ \\
\hline getting on with others & $x$ & $x$ & $x$ \\
\hline eating & $x$ & $x$ & \\
\hline sleeping & $x$ & $x$ & $x$ \\
\hline Wellbeing of family & $x$ & $x$ & $x$ \\
\hline Free description of concern & $x$ & $x$ & $x$ \\
\hline $\begin{array}{l}\text { Wish for school doctor's assessment of these } \\
\text { or other concerns }{ }^{c}\end{array}$ & $x$ & $x$ & $x$ \\
\hline
\end{tabular}

${ }^{a}$ Response options for each area of concern on a five point Likert scale: $0=$ Not at all, $1=$ Only a little, $2=$ Quite a lot, $3=$ A great deal, $4=I$ don't know ${ }^{b}$ Specified in parent's questionnaire: recurrent pain, prolonged complaints, skin symptoms, undescended testes

${ }^{c}$ Response options on a three-point scale: 2 =yes, $1=1$ don't know, $0=$ no

Possible benefit and harm of a school doctor's health check will be evaluated separately based on 1) the school doctors' interventions and reports of benefit or harm and 2) the PREMs (Table 2).

\section{Secondary outcomes}

The secondary outcome measures are 1) the interventions and follow-up plans arising from school doctors' routine health checks and 2) the implementations of measures from the doctor's electronic report after a follow-up period of 12 months (Fig. 1, box Interventions). The implementation of the measures will be categorized into three groups (yes, no, information not accessible).

\section{Statistical methods}

Sample size was calculated to detect $20 \%$ difference ( $25 \%$ vs $45 \%$ ) in the benefit between children who need and children who do not need a doctor's health check. Based on the pilot study, $25 \%$ of children who did not have a need for a doctor's health check could benefit from one. To account for the clustered nature of the data, an intra-cluster (intra-school) correlation coefficient (ICC) of 0.06 was assumed. From each school, 25 children will participate from grade 1 and 25 children from grade 5 . The required sample size is 450 children from both grades. Allowing for about 15\% of missing data regarding the need for a health check and/or
PREMs, the number of recruited children will be altogether 1050 from 21 schools.

Frequencies, percentages, means (with standard deviations; or in case of skewed distribution, medians with interquartile ranges) will be used as descriptive statistics.

Intrarater and interrater reliability will be assessed. $\mathrm{KN}$ will evaluate the need for the doctor's health check and the benefit or harm of the doctor's health check of each child and 200 randomly selected cases for intrarater reliability. To assess interrater reliability, SK will evaluate the data of 200 randomly selected children. SK will repeat the evaluation of the same 200 children to assess her intrarater reliability. Any discrepancies will be resolved using a third researcher.

The need for a doctor's appointment and the benefit gained from it from the different people's point of view will be compared. Researchers are blinded to study questionnaire responses when analyzing the benefit of the doctor's appointment.

Multilevel logistic regression analyses will be conducted to account for the effect of covariates (e.g. doctors' work experience and differences between municipalities). Analyses will be done separately for children from grade 1 and grade 5 .

\section{Discussion}

This is a multicenter study assessing the potential benefits or harm of school doctors' routine health checks and the use of questionnaires to identify children who would be likely to benefit most from a school doctor's health check. The study aims to evaluate whether school doctors should routinely check all children at ages of seven and eleven, as is currently mandated by the law, or only the ones that adults are concerned about. If the need for a doctor's health check, as evaluated from the study questionnaires, predicts the researcher-evaluated benefit gained from the health check the questionnaires may be suitable for screening in the future. At one year after the health check, the implementation of the school doctors' interventions and follow-up plans will be analyzed, which enables us to evaluate the effects of school doctors' work.

The strengths of the study include the usability and generalizability of the results in several ways: 1 ) The study is conducted in a normal clinical setting of the children's regular health checks; 2) The doctors performing the health checks are blinded to the answers of the study questionnaires; and 3) The study includes schools and professionals from different municipalities and socioeconomic areas. The multi-informant approach may be helpful in identifying the need for support for both children and their families. A limitation of the study is that the developed questionnaires have not been widely tested. It is possible that the questionnaires function best in the Finnish school healthcare system since the organizational 
models of school health service systems differ greatly even within Europe [2]. Additional limitations are that children studying mainly in special education groups and children whose parents need an interpreter were left out. According to clinical knowledge, the school doctor's assessment is frequently beneficial if the child's special education needs have not been assessed in a specialist setting or if the child has not undergone a medical examination related to a new immigrant status.

The current Finnish school healthcare system offers equal service for all children in certain grades. The obligation to double check the children by both a nurse and a doctor leads to a situation in which most of the school doctor resources are allocated to health checks of asymptomatic children whom no-one is concerned about. Children in other year levels than grades 1, 5 and 8 receive very limited school doctor services. Many children with special needs, often related to social inequities, mental health and lifestyle related problems, could benefit from the school doctor's attention earlier and more often than is currently recognized and offered. School doctors have little time for multidisciplinary work in student welfare groups and for cooperation with family counseling, child welfare and secondary care. This can result in inefficient care and referrals of patients from one unit to another. A structured screening method that would be available at any time of the year would increase the timeliness of the school doctor's health check. If the finding of this study is that recognizing children most likely to benefit from school doctors' appointments is impossible using the developed screening method, we have provided scientific evidence to support the current practice of school doctors' routine health checks in Finland. However, more school doctor resources should be provided to school health care to ensure timely access to school doctors' evaluation in case of need regardless of school grade.

The study will increase our knowledge of the benefits or harm of school doctors' routine health checks and assess the developed screening method. We hypothesize that targeting the doctors' health checks to the children in greatest need would increase the quality of school health services.

\section{Additional files}

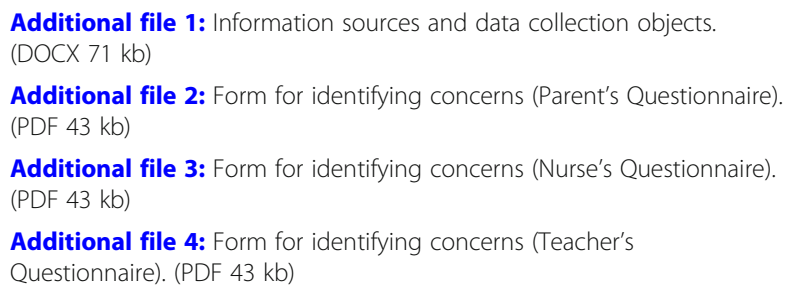

Additional file 5: Feedback form (Parent's patient-reported experience measure). (PDF $46 \mathrm{~kb}$ )

Additional file 6: Feedback form (Child's patient-reported experience measure). (PDF $42 \mathrm{~kb}$ )

\section{Abbreviations}

NQ: Nurse's Questionnaire; PQ: Parent's Questionnaire; PREM: Patientreported experience measure; SDQ: Strengths and Difficulties Questionnaire; TQ: Teacher's Questionnaire

\section{Acknowledgements}

The authors would like to thank all children, parents, school doctors, school nurses and teachers who participated in data collection. The authors would also like to thank biostatistician Tero Vahlberg for his help.

\section{Funding}

This study was supported by the Päivikki and Sakari Sohlberg Foundation, the Department of Social Services and Health Care, City of Helsinki, the Finnish Foundation for General Practice, the Network of Academic Health Centers, Finland and the University of Helsinki. The funding bodies did not have any role in the study design, data collection, management, analyses, interpretation of data, or writing of this manuscript.

\section{Availability of data and materials}

The datasets analyzed during the pilot study are not publicly available due to restrictions which were used under license for the study. Anonymous data are, however, available from KN or MK on request.

\section{Authors' contributions}

KN designed the study, collected, analyzed and interpreted the data of the pilot study and wrote the first draft of the manuscript. SK and MK made significant contributions to the design of the multicenter study and analysis plans and critically revised the manuscript. EH participated in the design and analyses of the pilot study, the design of the multicenter study and critically revised the manuscript. All authors approved the manuscript as submitted and are accountable for all aspects of the work.

\section{Ethics approval and consent to participate}

The coordinating ethics committee of the Hospital District of Helsinki and Uusimaa (HUS) has approved the study protocol (HUS/2174/2017). Permissions for the study have been obtained from the Departments of Social Services and Healthcare and the Departments of Education from all participating municipalities. Informed consent will be obtained from all participating children, parents, nurses, teachers and doctors. Consent covers also the storage of the research data for 10 years after the end of the study for possible further research in school health services by the research group. Personal data will be destroyed 5 years after they were collected. No biological specimens are collected for the purpose of this study. Data collection is partly organized digitally while taking care of appropriate data protection. The confidentiality of participants is protected by using an encryption key prior to data analyses. The key is stored separately from study data. All data will be treated according to national data security laws. If a significant concern were reported in the study questionnaires that was not discussed during the health check a new appointment will be arranged if necessary.

Consent for publication

Not applicable.

\section{Competing interests}

The authors declare that they have no competing interests.

\section{Publisher's Note}

Springer Nature remains neutral with regard to jurisdictional claims in published maps and institutional affiliations.

\section{Author details}

${ }^{1}$ School and Student Healthcare, Department of Social Services and Healthcare, City of Helsinki, Finland. 'Doctoral School in Health Sciences, 
Doctoral Program in Population Health, University of Helsinki, Helsinki, Finland. ${ }^{3}$ Medical Services for Children and Adolescents, Department of Social Services and Healthcare, City of Helsinki, Finland. ${ }^{4}$ Helsinki University Hospital, Children's Hospital and University of Helsinki, Helsinki, Finland. ${ }^{5}$ Public Health Medicine, University of Helsinki and Helsinki University

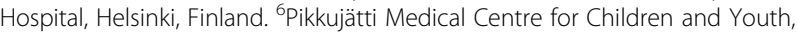
Helsinki, Finland.

Received: 11 March 2018 Accepted: 12 June 2018

Published online: 27 June 2018

\section{References}

1. Forrest CB, Riley AW. Childhood origins of adult health: a basis for life-course health policy. Health Aff (Millwood). 2004; https://doi.org/10.1377/hlthaff.23.5.155.

2. Baltag V, Levi M. Organizational models of school health services in the WHO European Region. J Health Organ Manag. 2013; https://doi.org/10. 1108/JHOM-08-2011-0084.

3. Baltag V, Pachyna A, Hall J. Global overview of school health services. Data from 102 countries. Health Behavior and Policy Review. 2015; https://doi.org/10.14485/HBPR.2.4.4.

4. Langford R, Bonell C, Jones H, Pouliou T, Murphy S, Waters E, Komro K, Gibbs L, Magnus D, Campbell R. The World Health Organization's Health Promoting Schools framework: a Cochrane systematic review and meta-analysis. BMC Public Health. 2015; https://doi.org/10.1186/s12889-015-1360-y.

5. Barlow J, Stewart-Brown S, Fletcher J. Systematic review of the school entry medical examination. Arch Dis Child. 1998:78:301-11.

6. Bezem J, Theunissen M, Buitendijk SE, Kocken PL. A novel triage approach of child preventive health assessment: an observational study of routine registrydata. BMC Health Serv Res. 2014; https://doi.org/10.1 186/s12913-014-0498-0.

7. Bezem J, van der Ploeg C, Numans M, Buitendijk S, Kocken P, van den Akker E. Preventive child health care at elementary school age: The costs of routine assessments with a triage approach. PLoS One. 2017; https://doi. org/10.1371/journal.pone.0176569.

8. Bezem J, Theunissen M, Kamphuis M, Numans ME, Buitendijk SE, Kocken P. A Novel Triage Approach to Identifying Health Concerns. Pediatrics. 2016; https://doi.org/10.1542/peds.2015-0814.

9. Goodman R. Psychometric properties of the strengths and difficulties questionnaire. J Am Acad Child Adolesc Psychiatry. 2001;S0890-8567(09): 60543-8.

10. Goodman R. The extended version of the Strengths and Difficulties Questionnaire as a guide to child psychiatric caseness and consequent burden. J Child Psychol Psychiatry. 1999;40:791-9.

11. Goodman A, Goodman R. Population mean scores predict child mental disorder rates: validating SDQ prevalence estimators in Britain. J Child Psychol Psychiatry. 2011; https://doi.org/10.1111/j.1469-7610.2010.02278.x.

12. Borg AM, Salmelin R, Joukamaa M, Tamminen T. Cutting a long story short? The clinical relevance of asking parents, nurses, and young children themselves to identify children's mental health problems by one or two questions. ScientificWorldJournal. 2014; https://doi.org/10.1155/2014/286939.

13. Saari A, Sankilampi U, Hannila ML, Kiviniemi V, Kesseli K, Dunkel L. New Finnish growth references for children and adolescents aged 0 to 20 years: Length/height-for-age, weight-for-length/height, and body mass index-forage. Ann Med. 2011; https://doi.org/10.3109/07853890.2010.515603.

14. Rosen DS. American Academy of Pediatrics Committee on Adolescence. Identification and management of eating disorders in children and adolescents. Pediatrics. 2010; https://doi.org/10.1542/peds.2010-2821.

15. Mindell JA, Owens JA, Carskadon MA. Developmental features of sleep. Child Adolesc Psychiatr Clin N Am. 1999;8:695-725.

16. Beitchman JH, Young AR. Learning disorders with a special emphasis on reading disorders: a review of the past 10 years. J Am Acad Child Adolesc Psychiatry. 1997:S0890-8567(09):62610-1.

17. Stempel H, Cox-Martin M, Bronsert M, Dickinson LM, Allison MA. Chronic School Absenteeism and the Role of Adverse Childhood Experiences. Acad Pediatr. 2017;S1876-2859(17):30493.

18. Beardslee WR, Versage EM, Gladstone TR. Children of affectively ill parents: a review of the past 10 years. J Am Acad Child Adolesc Psychiatry. 1998;11:1134-41.

\section{Ready to submit your research? Choose BMC and benefit from:}

- fast, convenient online submission

- thorough peer review by experienced researchers in your field

- rapid publication on acceptance

- support for research data, including large and complex data types

- gold Open Access which fosters wider collaboration and increased citations

- maximum visibility for your research: over $100 \mathrm{M}$ website views per year

At BMC, research is always in progress.

Learn more biomedcentral.com/submissions 